\title{
Improving biotech education through gamified laboratory simulations
}

Bonde, Mads; Makransky, Guido; Wandall, Jakob; Larsen, Mette Voldby; Morsing, Mikkel; Jarmer, Hanne Østergaard; Sommer, Morten

Published in:

Nature Biotechnology

Link to article, DOI:

$10.1038 / \mathrm{nbt} .2955$

Publication date:

2014

Document Version

Peer reviewed version

Link back to DTU Orbit

Citation (APA):

Bonde, M., Makransky, G., Wandall, J., Larsen, M. V., Morsing, M., Jarmer, H. Ø., \& Sommer, M. (2014). Improving biotech education through gamified laboratory simulations. Nature Biotechnology, 32(7), 694-697. https://doi.org/10.1038/nbt.2955

\section{General rights}

Copyright and moral rights for the publications made accessible in the public portal are retained by the authors and/or other copyright owners and it is a condition of accessing publications that users recognise and abide by the legal requirements associated with these rights.

- Users may download and print one copy of any publication from the public portal for the purpose of private study or research.

- You may not further distribute the material or use it for any profit-making activity or commercial gain

- You may freely distribute the URL identifying the publication in the public portal

If you believe that this document breaches copyright please contact us providing details, and we will remove access to the work immediately and investigate your claim. 


\title{
Improving biotech education through gamified laboratory simulations
}

\author{
Mads T. Bonde, ${ }^{1,2}$ Guido Makransky, ${ }^{3}$ Jakob Wandall, ${ }^{4}$ Mette Voldby Larsen, ${ }^{1}$ Mikkel Morsing, ${ }^{5}$ \\ Hanne Jarmer ${ }^{2}$ \& Morten O.A. Sommer, \\ ${ }^{1}$ Novo Nordisk Foundation Center for Biosustainability, Technical University of Denmark, ${ }^{2}$ Department of Systems \\ Biology, Technical University of Denmark, ${ }^{3}$ Department of Psychology, University of Southern Denmark, \\ ${ }^{4}$ NordicMetrics, Denmark, ${ }^{5}$ Department of Biology, University of Copenhagen, Denmark
}

Traditional teaching methods are dominating science education, but new IT-based approaches may provide an opportunity for increasing the skill level of students and motivate young people to pursue studies within the field. Laboratory teaching is limited by many practical barriers such as cost, safety and time, making it an especially relevant area for implementing simulations. In this study we show a $76 \%$ increase in learning outcomes by using a gamified laboratory simulation (Labster) compared to traditional teaching and a $101 \%$ increase when used in combination, suggesting an untapped potential for increasing the skills of science students and graduates.

A large proportion of high school and college students indicate that they have little interest in science, and many students graduate with marginal science competencies ${ }^{1,2}$. It has been suggested that this results from an exaggerated focus on memorizing facts, listening passively to lectures and performing 'cookbook' laboratory exercises in science education, rather than stimulating students' natural curiosity, and highlighting the intricate connection between science and "real world problems"3. Although several studies have challenged the effectiveness of traditional teaching methods ${ }^{4-8}$, these methods continue to dominate science education. This is not only problematic for students but is a major challenge for the biotech industry, which depends on highly educated graduates with up-to-date knowledge and skills.

A recent report published by the US National Research Council regarding the use of computer games and simulations in education analyzed all available studies and con-

Hanne Jarmer and Morten O.A. Sommer have shared senior authorship. Correspondance should be addressd to mab@bio.dtu.dk,hanne@cbs.dtu.dk,or msom@bio.dtu.dk cluded that "simulations and games have great potential to improve science learning in elementary, secondary and undergraduate science classrooms"2. Moreover, the US Department of Education's National Education Technology Plan states, "The challenge for our education system is to leverage the learning sciences and modern technology to create engaging, relevant and personalized learning experiences for all learners that mirror students' daily lives and the reality of their futures"9.

Because laboratory experiments can be expensive, time consuming and occasionally constrained by safety concerns, laboratory courses as an adjunct to classroom lectures are often the first classes to be removed from a curriculum. This is unfortunate because several theoretical science courses benefit from an experimental counterpart. Particularly within biotech, new techniques and methods are constantly enhancing and replacing existing research practices, and these developments soon become essential knowledge for biotech professionals. Nevertheless, the latest equipment and consumables are often prohibitively expensive, making it almost impossible for universities and schools to provide students with access to updated equipment such as nextgeneration DNA sequencing machines.

In response to this need, several simulations have been developed for science education, most of which focus on symbolic representations of experiments wherein students can alter parameters and simulate different outcomes. De Jong et al. ${ }^{10}$ recently reviewed studies comparing physical and simulated laboratory education and concluded that both physical and virtual laboratories "can achieve similar objectives such as exploring the nature of science, developing teamwork abilities, cultivating interest in science, promoting conceptual understanding and developing inquiry skills." Although physical laboratories are required for students to develop practical laboratory skills, virtual laboratories offer several other advantages, including allowing students to explore unobservable phenomena, enabling learners to conduct a number of experiments in a short period of time and providing adaptive guidance ${ }^{11}$. However, most simulations are primarily focused on accurately imitating physical phenomena and not on optimizing student learning ${ }^{12}$.

A recent literature review identified only a few studies that compared traditional classroom teaching with the use of simulations in biotech teaching between 2001 and 2010 (refs. 13-15). One study reported an increase in students' usage of accurate explanations after using a bioinformatics simulation ${ }^{15}$, and others reported a significant increase in test scores using a simulation based on cell theory ${ }^{14}$. Similarly, a learning effect was demonstrated using the simulation MyDNA, a program that involves a two-dimensional representation of gel electrophoresis wherein students can alter voltage and gel concentrations and then observe the differential speed of DNA fragments ${ }^{16}$.

Educational games are increasingly being used for learning biotech. Sadler et al. ${ }^{17}$ reported the implementation of a threedimensional (3D) biotech educational game (Mission Biotech), wherein gaming features were highlighted. A high learning outcome, particularly with lower-level students, was observed. Research regarding the effectiveness of games for science education is only beginning to emerge ${ }^{2}$, and to our knowledge no prior research studies performed to assess 


\section{NATURE BIOTECHNOLOGY volume 32 Number 7 July 2014}

the effectiveness of gamified simulations for enhancing biotech education have included a scientific design with control groups.

We hypothesized that combining gamification elements with simulations may provide an opportunity for even greater gains in learning effectiveness and motivation of biotech students. We developed and tested an advanced laboratory simulation platform based on mathematical algorithms supporting open-ended investigations and combined this with gamification elements such as an immersive 3D universe, storytelling, conversations with fictional characters and a scoring system. We then set out to assess the effect on learning effectiveness and motivation to investigate whether gamified laboratory simulations may be an affordable opportunity for providing state-of-the-art training in biotech.

\section{Development of a gamified biotech laboratory simulation}

Ten gamified laboratory simulations have been developed, two of which were tested: a crime-scene lab and a genetic engineering lab (www.labster.com) (Fig. 1). In the crimescene case, students start by explor- ing a crime scene that reveals an engaging story and then proceed to analyze blood samples from the scene using PCR and gel electrophoresis. Through scientific inquiry, students ultimately provide conclusive evidence to convict the perpetrator. Interactive $3 \mathrm{D}$ animations of microscopic events pause while students answer questions and identify elements and processes in animations. If a student convicts an innocent suspect, he or she experiences consequences of not adhering to scientific methods through a critical virtual newspaper article received during the gamified simulation. In the genetic engineering case, students embark on a mission to produce medicine and test it on a virtual mouse through molecular cloning, fermentation and animal experiments.

In developing these simulations, one of our key priorities was providing a realistic and immersive laboratory environment and 3D animations. We chose these because previous studies have demonstrated increased learning effectiveness among students who use highly realistic animations and because their use is supported by cognitive theories of multimedia learning and picture comprehension ${ }^{18-20}$. Simulations were designed for an inquirybased approach in which students must deduce and apply necessary actions by acquiring knowledge from integrated text and figures. Inquiry-based methods have been found difficult to successfully implement in classical teaching with a single teacher and numerous students $^{21-23}$. However, computer-based laboratory simulations may offer a framework for an effective and feasible solution.

A combination of learning and assessment methods, as described in recent research ${ }^{24}$, was integrated into the simulation through built-in, multiple-choice test items triggered by specific actions. In the simulation, students were asked to select a response until the correct answer was identified, and they were subsequently presented with an explanation of why the answer was correct. Immediate feedback inspires students to reflect on their choices of specific laboratory procedures, thereby improving their understanding of the underlying theory. Furthermore, to increase students' understanding of molecular details invisible to the human eye, $3 \mathrm{D}$ animations were integrated to demonstrate what happens at the molecular level as a direct consequence of laboratory actions performed by students.

\section{Motivation and self-efficacy}

Recent studies indicate noncognitive skills such as motivation and conscientiousness as crucial factors in the efficient development of cognitive skills in science learning ${ }^{25-27}$. Many students have a general perception of science as being boring and disconnected from the real world. For instance, approximately $50 \%$ of the students surveyed in physics classes found the subject "boring" or "very boring" 28 . We wanted to investigate whether gamified laboratory simulations could stimulate a higher degree of motivation for studying biotech. We set up a program to assess the genetic engineering lab in an online AP Biology class at the Stanford University Online High School (Stanford, CA, USA). We immediately followed the completion of the labs by an online questionnaire on motivation and interest. Forty out of $41 \mathrm{stu}$ dents found the laboratory simulation "interesting and relevant subject matter" and 23 out of 41 found it "more motivating than classroom or home wet labs."

We conducted a larger study of the more advanced crime-scene lab with 149 students from two biology classes at Archbishop Williams High School (Braintree, MA, USA) and in an introductory college-level life science course at the Technical University of Denmark (DTU). A high level of motivation was measured, as $97 \%$ of 149 students found it interesting to use the simulation; $86 \%$ indicated that the laboratory simulation was more interesting compared with ordinary exercises; and $97 \%$ felt that the course content was more interesting when working with gamified simulations (Fig. 2). Furthermore, $89 \%$ of users indicated that they learned something by using the gamified simulation, which indicates a high level of perceived learning and self-efficacy. Further studies in which students experience repeated use of simulations are needed to investigate how motivation and interest are affected when students become accustomed to using simulations in learning.

We also conducted a study on 57 students from four Danish high schools. Forty-four percent of the students agreed or completely agreed with the statement, "I consider pursuing an education within biotechnology or other biological subject to a greater extent, after having used the gamified laboratory simulator." This indicates that gamified laboratory simulations may provide a powerful case for initiatives to increase students engagement and motivation for further studies and careers within biotech. Large-scale longitudinal studies measuring the actual study and career choices of students exposed to gamified laboratory simulations compared with a control group would be valuable to guide future decisions.
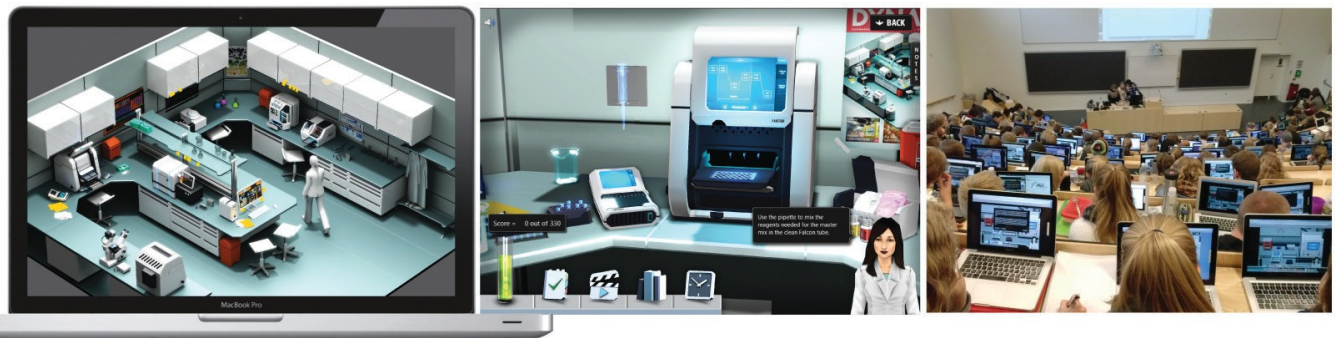

Figure 1 Screenshots from the gamified laboratory simulation tested in this study (Labster, www.labster.com) (left, center).

Students used the simulations from regular computers at home (in the case of testing at Stanford University Online High School) or in class (right). 


\section{NATURE BIOTECHNOLOGY volume 32 Number 7 July 2014}

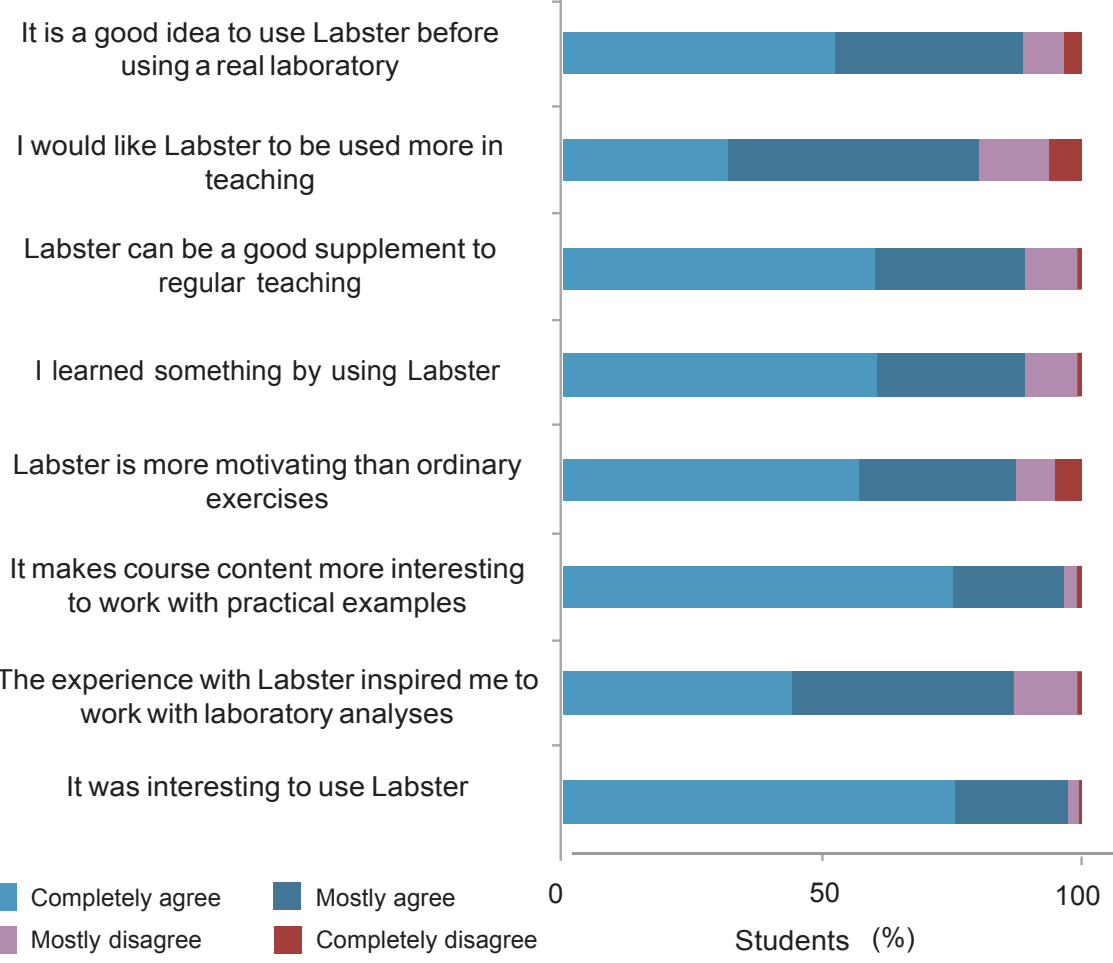

Figure 2 Survey results from 149 students from Stanford University Online High School, archbishop Williams High School and the technical University of denmark after using the gamified laboratory simulation crime-scene lab.

\section{Improved learning outcomes}

To assess the learning effectiveness of the gamified simulation compared with traditional teaching, we conducted a study testing the crime-scene case in an introductory, college-level, life science course with 91 students at DTU. All participants answered a pre-test consisting of 40 multiple-choice questions intended to fit an item response theory educational measurement model ${ }^{29,30}$. Students were then divided into two groups (alphabetically by first name). In the first lesson, Group A received a traditional lecture including a group excercise, and Group B performed the crime-scene simulation. Following the first lesson, all students were administered a mid-test comprising the same questions. In the second lesson, students switched conditions: Group A performed the laboratory simulation, and Group B received the lecture. After the second lesson, all students were administered the test again as a post-test. Students took the test for the fourth time 40 days later as a retention test. Test results were analyzed by fitting the data to the two parameter logistic (2PL) item response theory model that describes, in probabilistic terms, the relationship between an individual's response to a test item and his or her standing on the construct being measured by the test ${ }^{31,32}$. Of 40 items used on the test, 38 items fitted the 2PL model, indicating that the test was suitable for measurement of student skills. By comparing test results of the pre-test, mid-test, post-test and retention tests for each student on the 38 items, learning outcomes of each session could be assessed.

Students' scores improved by 1.48 standard deviation (s.d.) units from a mean $Z$ score of -1.37 to 0.11 after the laboratory simulation but only by 0.84 s.d. units from -1.20 to -0.36 after traditional teaching at the mid-test sampling point (Fig. 3). The results demonstrate that using the laboratory simulation led to significantly improved learning outcomes (76\% higher score) compared with traditional teaching $(t(89)=-4.37, P<0.0005)$. Effects of combining the simulation with traditional teaching were assessed with the post-test, and the measured learning outcomes were greater than any one of the methods alone $(t(90)=-7.49, P<0.0005$; see Fig. 3b) .

Students who used the simulation first had a $4.2 \%$ greater gain in measured learning outcomes compared with those who received traditional teaching first; however, this difference was not statistically significant (comparison of post-tests, $t(89)=-0.383, P=0.702$ ). This finding was consistent with those of previous studies ${ }^{16}$, indicating flexibility in the order of methods used and in integration possibilities for simulations. For instance, simulations could be used as a homework assignment as a pre-laboratory or post-laboratory activity in combination with traditional teaching. In fact, the traditional teaching increased learning outcomes by only $14 \%$ after students had completed the gamified simulation, which suggests that traditional teaching was almost redundant after the gamified simulation. However, the combination may have the strongest impact, particularly on long-term retention, because practicing new skills only once can lead to rapid deterioration of acquired competencies ${ }^{11}$. To test the durability, we administered a followup test 40 days after the sessions, and learning was found to be well retained; no significant difference was observed between scores on the a

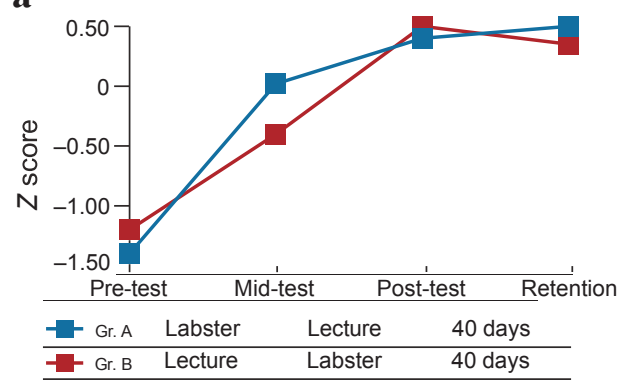

b

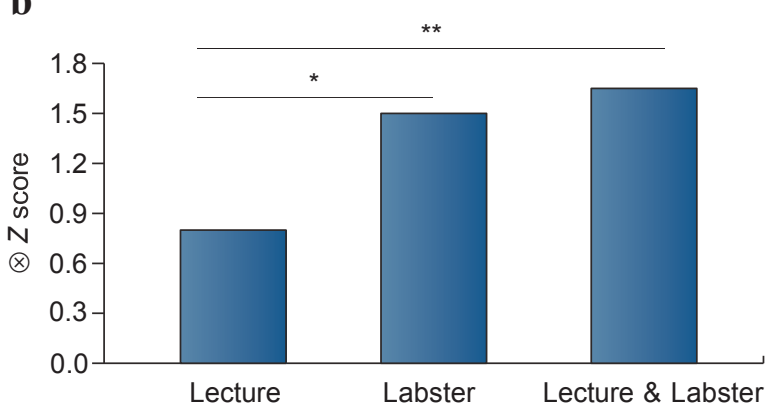

Figure 3 measurement of learning outcomes from 91 students. (a) test outcome of groups a and B receiving the laboratory simulation (Labster) and lecture including group exercise (Lecture) in the opposite order. (b) increase in learning outcomes observed after students attended a session with a lecture including group exercise (Lecture), laboratory simulation (Labster) and both methods combined. $*$ Students $t$-test, $t(89)=-4.37, P<0.0005$; $* * t(90)=-7.49, P<0.0005$. 


\section{NATURE BIOTECHNOLOGY volume 32 Number 7 July 2014}

post-test and the follow-up test $(t(87)=0.641$, $P=0.523)$.

\section{Gamified laboratory simulations as an integral part of future biotech education?} This study indicates that a gamified laboratory simulation can significantly increase both learning outcomes and motivation levels when compared with, and particularly when combined with, traditional teaching. Further research is urgently needed to investigate whether our results can be extrapolated to a general tendency of the effectiveness of gamified simulations. If our results represent a general tendency, increased focus in this area could provide an important opportunity to address some of the current challenges that science education is facing and ultimately to enhance science education.

Currently, simulations and games are used only sporadically in biotech education, perhaps because educational institutions still are more focused on delivering instructions than producing learning outcomes ${ }^{33}$. Other sectors have successfully integrated simulations as a well-established part of training. For instance, flight simulators have been successfully used for decades in training sessions of aspiring pilots, and combining simulations with real airplaneflying experience has proven to be more effective with regard to both time and resources ${ }^{34}$. Particularly within biotech education, gamified simulations can benefit students by providing simulated access to exercises that would otherwise require expensive equipment and hazardous techniques that most educational institutions are unable to offer. To fully explore and deploy the potential of gamified simulations in biotech education, policymakers, end users such as school districts and universities, researchers and companies must work together to develop, research and assess new gamified simulations to reap benefits of modern technology for the improvement of science education.

\section{ACKNOWLEDGMENTS}

We would like to acknowledge H.J. Genee, P. Rugbjerg, J. Serritslev, A. Laustsen, D. Møller, L. Holst, S. Heilmann, O. Filtenborg, E.B. Hansen, S. Molin, O.D. Madsen, B. Nauntofte, R. Frandsen, O. Thastrup, H.H.Wang, P. Falholt, J. Vind,

J.T. Andersen, T. Damhus, B.T. Simonsen, C.B. Jorgensen, C.V.S. Bruun, K. Spohr, P. Gibson, J. Keasling, G.M. Church, J. Nielsen and B. Palsson for fruitful discussions, support and advice. We would also like to thank the Labster team for codevelopment of the gamified laboratory simulations, H. Bonde, G. Nixon and E. Earls for critical reading of the manuscript, as well as K. Failor and M. Huang for collaboration regarding the tests at Stanford University OHS and Archbishop Williams High School. We would like to acknowledge the student organization Biotech Academy at DTU for its role in disseminating science education and awareness to the young. This research was funded by the Novo Nordisk Foundation and the Danish Market Development Fund, and the development of the laboratory simulations has been supported by The Danish Ministry of Science, the Danish Market Development Fund, The Lundbeck Foundation, The Danish Film Institute, Novo Nordisk A/S and Novozymes A/S.

1. Business Higher education Forum. the Stem interest and Proficiency challenge: creating the Workforce of the Future (Washington, dc, 2011).

2. Honey, m.a., et al. Committee on Science Learning. Computer Games, Simulations, and Education. (national research council, 2011).

3. Gago, J.m. et al. Increasing Human Resources for Science and Technology in Europe. european commission High Level Group report (2004).

4. Lanahan, L., meGrath, d.J., mcLaughlin, m., Burian-Fitzgeral, m. \& Salganik, L. 1-32, Fundamental Problems in the Measurement of Instructional Processes: Estimating Reasonable Effect Sizes and Conceptualizing What is Important to Measure (american institutes for research, Washington, dc, 2005).

5. alexander, K., natriello, G. \& Pallas, a.m. Am. Sociol. Rev. 50, 409-420 (1985).

6. natriello, G., Pallas, a. \& alexander, K. Sociol. Educ. 62, 109-118 (1989)

7. ralph, J., Keller, d. \& crouse, J. Phi Delta Kappan 76, 144-150 (1994)

8. Keller, d. an assessment of national academic achievement Growth (University of delaware, 1995).
9. the US department of education's national education technology Plan. Transforming American Education: Learning Powered by Technology (2010).

10. de Jong, t., Linn, m.c. \& Zacharia, Z.c. Science $\mathbf{3 4 0}$ 305-308 (2013)

11. Zacharia, Z.c., Olympiou, G. \& Papaevripidou, m. J. Res. Sci. Teach. 45, 1021-1035 (2008).

12. mislevy, r.J. Evidence-centered design for simulationbased assessment. creSSt report 800 (national center For research on evaluation, Standards, and Student testing, Los angeles, 2011).

13. rutten, n., van Joolingen, W.r. \& van der Veen, J.t. Comput. Educ. 58, 136-153 (2012).

14. Kiboss, J.K., ndirangu, m. \& Wekesa, e.W. J. Sci. Educ. Technol. 13, 207-213 (2004).

15. Gelbart, H. \& Yarden, a. J. Biol. Educ. 40, 107-112 (2006).

16. toth, e.e., morrow, B.L. \& Ludvico, L.r. Innovative High. Educ. 33, 333-344 (2009).

17. eastwood, J.L. \& Sadler, t.d. Comput. Educ. 66 11-24 (2013).

18. Höffler, t.n. \& Leutner, d. Learn. Instr. 17, 722-738 (2007).

19. mayer, r.e. Multimedia Learning (cambridge University Press, 2001).

20. mayer, r.e. in The Cambridge Handbook of Multimedia Learning (ed. r.e. mayer) (cambridge University Press, 2005)

21. Gormally, c., Brickman, P., Hallar, B. \& armstrong, n. J. Coll. Sci. Teach. 40, 45-52 (2011).

22. anderson, r.d. J. Sci. Teach. Educ. 13, 1-12 (2002).

23. donnelly, d., O'reilly, J. \& mcGarr, O. Res. Sci. Educ. 43, 1571-1592 (2012)

24. the Gordon commission on the Future of assessment in education. To Assess, to Teach, to Learn: a Vision for the Future (Princeton, nJ, 2013).

25. Levin, H.m. Prospects 42, 269-284 (2012).

26. Heckman, J.J. Econ. Inq. 46, 289-324 (2008).

27. Singer, S.r. etal.America's Lab Report: Investigations in High School Science. Committee on High School Science Laboratories: Role and Vision (the national academies Press, Washington, dc, 2005).

28. national Foundation for educational research. Exploring Young People's Views on Science Education. report to the Wellcome trust (http://www.nfer.ac.uk/ publications/999901; 2011).

29. masters, G.n. Psykometrika 47, 149-174 (1982).

30. embretson, S.e. \& reise, S.P. Item Response Theory for Psychologists (Lawrence erlbaum associates, mahwah, nJ, 2000).

31. Wainer, H., Bradlow, e.t. \& Wang, X. Testlet Response Theory and its Applications (cambridge University Press, 2007).

32. Birnbaum, a. in Statistical Theories of Mental Test Scores (eds. F.m. Lord \& m.r. novick) 395-479 (addison-Wesley, reading, ma, 1968)

33. Barr, r.B. \& tagg, J. Change 27, 12-26 (1995)

34. Hays, r.t., Jacobs, J.W., Prince, c. \& eduardo, S. Mil. Psychol. 4, 63-74 (1992). 